\title{
Behavioral Factors in Rotational Grazing Systems
}

\section{By Mark W. Brunson and Elizabeth A. Burritt}

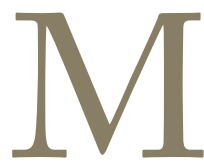

any in the range profession are perplexed by the apparent discrepancy between experimental studies suggesting that rotational grazing carries no advantage over continuous grazing ${ }^{1}$ and the observations of ranchers and range managers who have personally seen benefits for livestock production and plant communities by shifting to a rotational system. ${ }^{2,3}$ We believe one reason for this seeming contradiction is that research on plant and animal production is typically designed to control for the effects of behavior of grazing animals and their owners. As researchers who have spent many years studying the behavior of range livestock and people, we argue that understanding human and animal behavior as it relates to grazing management can help to bridge the gap between science and practice. In this paper we discuss how livestock behavior factors (such as prior experience and stress) and managers' learning processes can influence the outcomes of grazing management practices, why a standard experimental approach may not detect those influences, and how an improved knowledge of behavior can help both ranchers and researchers achieve their goals with respect to rotational grazing systems.

\section{Behavior and the Scientific Process}

Before discussing behavioral factors in grazing management, we would like to explore briefly the behavioral factors in experimental science that may help to explain why research results do not seem to match experience with rotational grazing. There is a long and illustrious history of using experimental methods to study behavior. Many of the greatest breakthroughs in psychology came from carefully controlled experiments with human subjects. Similarly, behavioral researchers use animal models in experiments to understand both human and animal behavior. ${ }^{4,5}$ In our own profession, hundreds of experiments have been published examining aspects of livestock behavior with regard to diet and habitat selection, social influences, effects of stress, and how animals learn. In this paper we are guided by the experimental studies of herbivory by Fred Provenza along with collaborators that include Beth Burritt, the second author of this paper. ${ }^{6, \mathrm{i}}$

'For an overview of this work see BEHAVE: Behavioral Education for Human, Animal, Vegetation \& Ecosystem Management (http://www. behave.net) or Provenza. ${ }^{6}$
Yet when the topic of study is not behavior, researchers go to great lengths to filter out its potentially confounding effects. Behavior can vary over time and from individual to individual, whether the individual is an experimental subject or a researcher. Therefore scientific protocols typically spell out very specific steps that must be taken whenever a treatment is administered or a measurement is taken in order to reduce the potential effects of variations in how experimenter and subject behave during the trial.

Researchers conducting animal studies often try to limit variability by using animals similar in age, breed, and sex; they are less likely to consider how prior experiences can profoundly affect their experimental animals. Numerous studies show that experiences early in life affect acceptance and preference for different foods. ${ }^{7-10}$ Habitat use and foraging skills also are influenced by prior experience, and these can influence how effectively an experimental animal adapts to its new surroundings. ${ }^{11,12}$ Social scientists, especially survey researchers, take an opposite tack: they incorporate enough different individuals into a study that the differences between respondents are averaged out, and a statistically derived picture emerges of a "typical" individual.

While such approaches are valid and have greatly increased our certainty about scientific phenomena, these approaches have pitfalls. In their search for statistical power and rigor, scientists who tightly control or fail to control for behavioral variation may have to create artificial situations that do not match the conditions under which the results will be applied. Just as a researcher's behavior must be consistent, a successful grazing manager's behavior must be adaptive, changing over time as influenced by information and experience. Similarly, livestock engage in behaviors that are shaped by consequences (intentionally or unintentionally) to produce desirable or undesirable outcomes.

Experiments isolate the effects of one or a few factors (e.g., grazing frequency, timing, or intensity) on a particular variable (e.g., forage production). However, a livestock operation is a complex system. It may be difficult to isolate particular factors and to predict how the entire system will respond. To exclude the confounding effects of year-to-year climate variation, grazing systems studies normally compare effects of different systems on similar tracts of land in the 
same year or the same system on the same tract in different years. This differs from the evaluations made by ranchers that report beneficial effects of switching to rotational grazing by comparing effects of different systems on the same tract in successive years. A ranch manager using continuous grazing is most likely to switch to a rotational system when there do not seem to be any other viable alternatives. Successful managers of any sort of enterprise rarely switch from something that is working to something that may or may not work; they switch when they believe that what they have been doing is no longer working. Thus the shift to a rotational system most often occurs when a rancher sees his or her operation on a downward trajectory (real or perceived) or unlikely to survive (or to provide a desired level of economic and non-economic benefits) without radical intervention.

\section{Rancher Behavior and the Nature of Change}

In their synthesis of research on rotational versus continuous grazing, Briske et al. ${ }^{1}$ acknowledged the behavioral factor when they observed that "long-standing controversy very likely originates from managerial emphasis on the socioeconomic benefits of the ranch enterprise while research scientists focus on ecological processes" (p. 10). We believe they were half right. Certainly ranchers monitor socioeconomic benefits, and a noticeable decline in these benefits may be likely to trigger a significant change in management. But progressive, successful ranchers also focus to a significant extent on ecological processes, although they may interpret them differently than scientists do. This is one reason why they remain successful.

In our work with ranchers and other range managers, we often hear common-sense axioms that describe the nature of management change. Research has shown how and why these axioms actually work. One such truism is that change is a constant-as the Greek philosopher Heraclitus wrote, "You could not step twice into the same river, for other waters are ever flowing on to you." This is one of the most attractive aspects of ranching. No two days are alike. Animals change with the seasons as does the land. But when small changes happen constantly, it is easy to miss important trends. Changes can go unnoticed until they reach crisis proportions. For self-employed ranchers, an economic "crisis" may be noticeable sooner than an ecological one.

A recent study of ranchers' adoption of new practices in Colorado $^{13,14}$ identified two types of management change: corrective change, an adjustment in an existing practice such as moving a fence, adding a water development, or going to market a week or two earlier; and substantive change, adopting a new approach to managing one's land, e.g., moving from feedlot to pasture finishing, or from a cow-calf operation to a stocker operation. Ranchers tend to make corrective changes quite easily; substantive changes are much rarer. Shifting from a continuous to a rotational grazing system is likely to represent a substantive change, in that typically (though not always) it requires changes in a timetested production calendar, short-term increases in labor, and often a significant investment in infrastructure such as fences and water developments.

A second, even better-known axiom is that change is difficult. We take comfort in the old saying, "If it ain't broke, don't fix it." The tendency for agricultural producers to retreat from change, rather than embrace it, has helped foster the extension profession. If change were easy, one could simply make new information available then stand back to avoid the rush of ranchers clamoring to apply it. Because change is hard, people try to avoid it. Agricultural producers may be especially likely to avoid change because the negative impacts of making a mistake are amplified in an operation that has only a single production cycle per year. Therefore we not only have trained extension professionals who learn to coax cautious clients into improving their practices, but also an entire branch of sociology that seeks to enhance rates of adoption of new technologies and management practices. ${ }^{15,16, \mathrm{ii}}$

Everett Rogers, the founder of adoption-diffusion research, described five features of innovations that affect the likelihood that they will be adopted. The most important of these is relative advantage, a manager's calculation of whether a change in practice is likely to lead to a better condition than before the change. Such a calculation may seem simple. Will my cattle gain more weight? Can I reduce operating costs without sacrificing profits?

But there is more to the equation: How easy is the new practice to learn? Will it take more time? Can I test it on a portion of my land, or do I have to go "whole hog?" Does it fit with my current operation, or must I change other aspects of my business to accommodate it? Can I tell easily whether it's making a difference? The harder it is for a rancher to answer these questions positively, the less likely he or she will be to make a change.

In the short run, a shift to rotational grazing can be more labor-intensive, especially at first before the cattle are trained to move easily from pasture to pasture (see discussion below). Also, a trial comparison of rotational versus continuous grazing is not easy in a practical setting, i.e., the vast majority of producers do not have enough of a land base to implement a rotational system on part of their property while maintaining continuous grazing elsewhere. Even though the basics of rotational grazing are easy to understand, the specific application to one's own property may require trial and error. For example, here is how one rancher described his efforts to use electric fencing in order to move cattle more often:

\footnotetext{
ii The best-known thread of social science on extension and technology transfer is the so-called "adoption-diffusion theory" of Everett Rogers. ${ }^{15}$ Other research traditions exist, however. One such publication that is especially relevant to range science and management is Ison and Russell. ${ }^{16}$
} 
The thing that helped us most was that three of us were trying to use it at home and talking back and forth about it. Plenty of failures. I don't have any of the first electric fence posts that I bought. None of them were right. Some of the chargers, the tape, the wire-all that stuff we changed.... So [we got there by] trial and error and also neighbors' trial and error. ${ }^{17}$

In our work with the Consortium for Behavioral Education for Human, Animal, Vegetation \& Ecosystem Management (BEHAVE) ${ }^{7-10}$ we often speak of the "3-year rule," i.e., the notion that any significant innovation takes time to learn-often about 3 years. The rule's name refers to the annual cycle of ranching. As retired Forest Service range manager Floyd Reed explained it, the first year after a change in grazing system is often a "wreck." The second year is not as bad, but there still are kinks to work out. By the third year-if the permittee persists into year 3-things work more smoothly than ever before. For example, a public land permittee who previously used a continuous system must learn when to move cattle, where they are likely to be when it is time to move to the next pasture, and how best to move them to that new pasture when the animals can make many wrong turns. In such cases it is easy to have a "wreck." Word about a wreck travels fast within the local ranching social network. It does not take many bad anecdotes to deter an already hesitant rancher from making a change. Conversely, given the length of time it takes to truly learn how to benefit from a new practice and the relatively slow pace of environmental improvement in semi-arid range environments, it may take a decade or more before real benefits are noticed.

If all this is true, why does anyone change grazing systems? As we noted previously, such a change often comes from a decline in net economic returns. It is broken, and fixing it means substantive change. Some places also have resources to make learning easier. Working in western Colorado, we began to identify a "culture of innovation" that arose because multiple sources of information, including a Range Management School for Ranchers ${ }^{17}$ and experts in Holistic Management, ${ }^{18}$ were locally available. As more ranchers used those resources, it became progressively easier for others to learn from the successes and wrecks of their neighbors.

This is because people are social animals. Everett Rogers ${ }^{15,16}$ pointed out that adoption decisions depend on characteristics of the innovation, as described above, characteristics of the potential adopter (e.g., life stage, financial resources or risk-aversion tendencies), and characteristics of the adopter's social system. In the previous paragraph, we saw how a supportive social system can make it easier to adopt a new practice. On the flip side, ranchers can be reluctant to make a substantive change in management if they believe their fellow ranchers will think less of them for going against the norm.
This is one place where financial and/or technical assistance from a federal agency, such as the Natural Resource Conservation Service's (NRCS) advocacy of prescribed grazing systems, ${ }^{19}$ can be important. A study of Utah's most innovative ranchers ${ }^{20}$ found that the structure of federal programs can have a significant influence on whether or not a practice is adopted. But that is just one of many potentially influential factors in a social system. The studies in Utah and Colorado found that adoption can also be influenced by ranchers' beliefs about the likely reactions of customers, lessors of public or private forage, and the general public.

Once a rancher does decide to make a change, he or she is likely to follow Napoleon's advice: "Take time to deliberate; but when the time for action arrives, stop thinking and go in." Ranchers tend to be "doers," accustomed to making quick decisions in a crisis. Once a change is madeespecially one requiring a substantial investment in both infrastructure (e.g., fences, water developments, etc.) and time- they will work extra hard to make it succeed. This helps to explain why stories abound of successful shifts to rotational grazing even though scientific research does not predict success. A rancher who makes a change in practice has made a large psychological as well as economic investment in that change. With such a strong incentive to succeed, a rancher is prepared to make all sorts of adjustments to assure success. This seat-of-the-pants form of adaptive management is contrary to the scientific process, wherein a protocol cannot be changed once an experiment has begun, even if it is clear that the original approach is not going to work.

For example, many rotational systems call for moving livestock when forage has reached a predetermined level of utilization. Thus, the system calls for adaptive management based on indicators that vary over time. Managers have the option of changing pasture size, stocking rate, stock density, length of time in a pasture, etc., depending on management goals. They can make changes quickly in response to changing conditions or to the impacts of management on plant production, and also to factors unrelated to utilization such as undesirable livestock behaviors. Conversely, most research protocols call for the scientist to rigorously follow the same procedures from start to finish. This is not to say that environmental conditions cannot dictate researchers' decisionsin fact, many studies have used a combination of utilization and standing crop as the decision criteria for moving animals just as ranchers would do-but the range of possible adjustments is narrower because consistency of procedure is vital in science.

Producers may look at other differences between their grazing management and research studies on rotational grazing and decide that the research is not applicable to their operation. For example, many practitioners of rotational grazing use high-density, short-duration grazing with many pastures or grazing cells. Of the 47 studies reviewed by Briske et al., $83 \%$ used fewer than eight pastures, whereas 
short-duration rotational systems on larger ranches can use several times that many pastures. Second, research studies typically use smaller pastures with fewer animals than most ranching operations; this means that the added benefit of changing distribution is less because distribution in a smaller pasture is likely to be less uneven initially.

Testimonials from fellow ranchers about increased carrying capacity, improved plant diversity and production, and higher economic returns are likely to have more influence on a rancher than research results. Many ranchers have good monitoring records that document rangeland improvement under a rotational system. For a rancher thinking about changing to a rotational system, photos documenting improvement in rangeland condition, monitoring data, and financial records from another ranch may be more compelling than any research study. After all, "Seeing is believing."

Other advantages of rotational grazing not thoroughly studied may include the following: reduced losses due to illness, injury, or theft (because cattle are monitored more often), gentler animals, flexibility to take advantage of unusual rainfall events, ability to stockpile forage for fall and winter grazing, improved relationships with agency personnel, improved wildlife habitat, and increased diet breadth (the variety of plant species eaten by livestock).

Lastly, ranchers who find themselves in financial trouble often make several changes at the same time. If the situation improves, ranchers may attribute most, if not all, of the improvement to changes in grazing management. However, in an attempt to save the ranch, improvement may not be due to the grazing system but simply due to their having become more attentive and creative managers.

\section{Livestock Behavior and Rotational Grazing}

Rancher behavior is only half of the behavioral story, however. Like people, cattle are social animals that learn from each other and individual experience. The behavioral tendencies of cattle help to explain why rotational grazing may be less effective in an experimental setting than in a working ranch. A producer who understands livestock behavior can also enhance the likelihood of success when making a change in grazing systems.

Animals, like people, prefer to live with companions rather than strangers. Cattle purchased from a variety of locations and mixed as a single experimental herd show more signs of stress than animals reared together. ${ }^{21}$ Mixing unfamiliar animals together may be more stressful in a rotational system than in a continuous system because animals are in closer proximity to one another when grazing.

Cow-calf operations typically retain the same animals from year to year, especially if they keep their own replacement females. Using the same animals year after year may produce better results in a grazing system because animals are familiar with the grazing system, animal handlers, locations of shelter and water, the vegetation, and their herd mates. However, most research studies use yearling heifers or steers to evaluate grazing systems. Using naive animals each year may affect results. For operations that graze stockers, some producers put an older cow with stockers to teach them the locations of forage, water, and cover on a rangeland; this is not a practice typically used in research.

A potential advantage of rotational grazing not often considered is that animals may learn to increase the number of plant species they eat.22,iii In a continuous system, livestock often eat only their preferred forages. But in a rotational system, as forage declines, animals are forced to eat less-preferred species. In the process, they learn to mix their diets to include preferred and less-preferred forages. Positive experiences with less palatable foods have been shown to change dietary preferences for those foods. $23,24, \mathrm{iv}$ Ranch livestock that do not learn to eat less-preferred species and continue to perform poorly will eventually be culled, thereby creating a "culture" of livestock that eat a wider variety of plant species. Thus, a rotational system may reduce the spread of undesirable species, may increase amount of forage available, and may improve rangeland quality. This benefit may be missed in grazing-system studies, which typically have not attempted to measure the species being consumed beyond very broad categories such as graminoids vs. forbs.

\section{Behavior-Based Management of Grazing Systems}

We began this paper by discussing why rigorous scientific research may not be able to explain the benefits of a rotational grazing system when implemented at the scale of a commercial ranch. The real question is not about why science and application are inconsistent, but rather it is about how we can use scientific findings along with reports of real-world success to improve the sustainability of livestock production on rangelands.

Animal scientists and practitioners increasingly agree on the importance of reducing the stress experienced by livestock when handled. ${ }^{25, v}$ One way to do so when applying a

\footnotetext{
iii For example, Canadian researchers found that cattle in a high-intensity, low-frequency rotational system learned to eat Canada thistle to the extent that thistle stems were virtually eliminated from the experimental pasture. $^{22}$

iv Work by Villalba et al. ${ }^{23}$ showed that experience with foods can dramatically change diet selection. Lambs that are experienced with foods containing tannins, oxalate, and terpenes eat over $800 \mathrm{~g}$ per day of those foods even when they have alfalfa and barely free choice. Sheep that are experienced with low-quality forage eat $20 \%$ more than inexperienced animals even if they have nutritious alternatives. Cattle can be trained to eat a variety of weeds, decreasing the weeds' abundance. For a rancher's report on this phenomenon, see Banister. ${ }^{24}$

$\checkmark$ The best-known proponent of low-stress handling is Bud Williams, whose workshops have been attended and lauded by many thousands of stock growers. For a scientist's view of stress in animals and ways to reduce it, see Grandin and Johnson. ${ }^{25}$
} 
new grazing system is to use animals that are already familiar with the landscape, as would be the case for ranchers running a traditional cow-calf operation. This may be impractical for researchers, however. To minimize effects of stress in a rotational grazing experiment, it would be best not to begin a study immediately, but to allow the animals time to become familiar with novel locations and plants, time to learn to respect electric fences, and time to grow comfortable with grazing under more crowded conditions.

Ranchers considering a shift to rotational grazing will be most successful if they think carefully about how it fits with their own behavioral patterns as well as those of others who are significant in their lives. Changes in management should fit one's life stage. For example, a rotational grazing system may be less viable for people who have constraints on their time such as a full-time job in town or an elderly parent needing hours of daily care. It is easier to make a substantive change in management practice when there are sources of support in the community than when there is likely to be opposition, and more importantly when one's family is supportive. A Colorado rancher who changed grazing systems after attending Holistic Management training described it this way:

When I thought I was going to come home and build fences, I ... got my son and daughter and wife to talk about what was important in their life. I mean that seems a long way from building fences and growing grass, but that's really the important part, because you can make all of those mechanical adjustments but if you don't get the deep down stuff of where you're headed in life with the rest of your family, it isn't so great. ${ }^{17}$

For researchers seeking to unravel the relative benefits of different grazing systems, the challenge is to design a study that mimics as much as possible the behavioral influences on success or failure in a ranching setting. If the experimental requirements for consistency of measurement and treatment preclude adaptive management midway through a grazing trial, perhaps it would be best to try another research approach altogether. For example, much could be learned from longitudinal research that employed a small number of case studies over 3 or more years. While many of our most familiar statistical tests could not be used, it is possible in such research to isolate the factors that are associated with a successful transition from continuous to rotational grazing but are not seen in operations where benefits are not seen. If the case study also entailed making the same kinds of utilization and animal production measures commonly used in experiments, it could be possible to determine whether the perceived benefits of rotational grazing are as real as many ranchers say they are.

There remains disagreement within our profession about whether a rotational grazing system is always, sometimes, or rarely superior to continuous grazing. What seems certain is that some ranchers have benefited from rotational grazing, and others will seek help from federal agencies to follow in their footsteps. In those instances, technical assistance programs should consider behavioral factors, for example by encouraging the use of alternative sources of information. Some ranchers do not trust government range conservationists but trust university extension; for others the reverse is true. Management change can be made more successful by promoting opportunities for ranchers to share information with each other, because that is where the trust is greatest and the expertise is most relevant.

\section{Acknowledgments}

Research described here was supported by the USDA Cooperative State Research, Education, and Extension Service as part of the BEHAVE program, and by the Utah Agricultural Experiment Station (UAES), Utah State University, Logan, Utah. This paper has been approved as UAES journal paper No. 8136 .

\section{References}

1. Briske, D. D., J. D. Derner, J. R. Brown, S. D. Fuhlendorf, W. R. Teague, K. M. Havstad, R. L. Gillen, A. J. Ash, AND W. D. Willms. 2008. Rotational grazing on rangelands: reconciliation of perception and experimental evidence. Rangeland Ecology and Management 61:3-17.

2. Goodloe, S. 2001. Four decades of understanding watershed degradation and our rehabilitation of the Carrizo Valley Ranch. In: New Mexico watershed management: restoration, utilization, and protection. Las Cruces, NM, USA: New Mexico Water Resources Research Institute. p. 1-10.

3. Sayre, N. F. 2001. The new ranch handbook. Santa Fe, NM, USA: Quivira Coalition. 101 p.

4. Pavlov, I. P. 1927. Conditioned reflexes. London, United Kingdom: Oxford University Press. 430 p.

5. Skinner, B. F. 1965. The behavior of organisms: an experimental analysis. Boston, MA, USA: Copley. 457 p.

6. Provenza, F. D. 2003. Foraging behavior: managing to survive in a world of change. Logan, UT, USA: Department of Forest, Range and Wildlife Resources, Utah State University. 63 p.

7. Wiedmeier, R. D., F. D. Provenza, and E. A. Burritt. 2002. Exposure to ammoniated wheat straw as suckling calves improves performance of mature beef cows wintered on ammoniated wheat straw. Journal of Animal Science 80: 2340-2348.

8. Distel, R. A., And F. D. Provenza. 1991. Experience early in life affects voluntary intake of blackbrush by goats. Journal of Chemical Ecology 17:431-450.

9. Mirza, S. N., and F. D. Provenza. 1990. Preference of the mother affects selection and avoidance of foods by lambs differing in age. Applied Animal Behavior Science 28:255-263.

10. Green, G. C., R. L. Elwin, B. E. Mottershead, and J. J. Lynch. 1984. Long-term effects of early experience to supplementary feeding in sheep. Proceedings of the Australian Society of Animal Production 15:373-375.

11. Howery, L. D., F. D. Provenza, R. E. Banner, and C. B. Scotт. 1998. Social and environmental factors influence cattle distribution on rangeland. Applied Animal Behavioral Science 55:231-244. 
12. Flores, E. R., F. D. Provenza, and D. F. Balph. 1989. The effect of experience on the foraging skill of lambs: importance of plant form. Applied Animal Behavioral Science 23:285-291.

13. Kennedy, C. A., And M. W. Brunson. 2006. Creating a culture of innovation in ranching: a study of outreach and cooperation in west central Colorado. Rangelands 29(3):35-40.

14. Kennedy, C. A. 2005. Learning and adoption of range management innovations among ranchers in west-central Colorado [thesis]. Logan, UT, USA: Utah State University. $104 \mathrm{p}$.

15. Rogers, E. M. 2003. Diffusion of innovations. 4th ed. New York, NY, USA: Free Press. 518 p.

16. Ison, R., And D. Russell. 2000. Agricultural extension and rural development: breaking out of knowledge transfer traditions. Cambridge, United Kingdom: Cambridge University Press. 239 p.

17. LeValley, R. B., J. Murray, F. Reed, J. Hawks, and D. BRADFORD. 2000. Range management schools for ranchers: or how to teach plant phenology, forage utilization, plant physiology, and other esoteric range management concepts to a bunch of cowboys. Rangelands 22(4):10-13.

18. Savory, A., And J. Butterfield. 1998. Holistic management: a new framework for decision making. Washington, DC, USA: Island Press. 616 p.

19. USDA Natural Resources Conservation Service. 2006. National range and pasture handbook, December 2006. Fort Worth, TX, USA: USDA NRCS. Chapter 5, Section 1(f), p. 8 .
20. Didier, E. A., And M. W. Brunson. 2004. Adoption of range management innovations by Utah ranchers. Journal of Range Management 57:330-336.

21. Mounier, I. Veissier, S. Andanson, E. Delvla, and A. Boissy. 2006. Mixing at the beginning of fattening moderates social buffering in beef bulls. Applied Animal Behavior Science 96:185-200.

22. DeBruijn, S. L., and E. W. Bork. 2006. Biological control of Canada thistle in temperate pastures using high density rotational cattle grazing. Biological Control 36:305-315.

23. Villalba, J. J., F. D. Provenza, and GouDong. 2004. Experience influences diet mixing by herbivores: implications for plant biochemical diversity. Oikos 107:100-109.

24. Banister, R. 1981. Eight principles of range management. Rangelands 13:85-86.

25. Grandin, T., and C. Johnson. 2009. Animals make us human: creating the best life for animals. New York, NY, USA: Houghton Mifflin Harcourt. 352 p.

Authors are Professor and Head, Dept of Environment and Society, Utah State University, Logan, UT 84322, USA, brunsonm@cc.usu.edu (Brunson); and Research Associate, Dept of Wildland Resources, Utah State University, Logan, UT 84322, USA (Burritt).

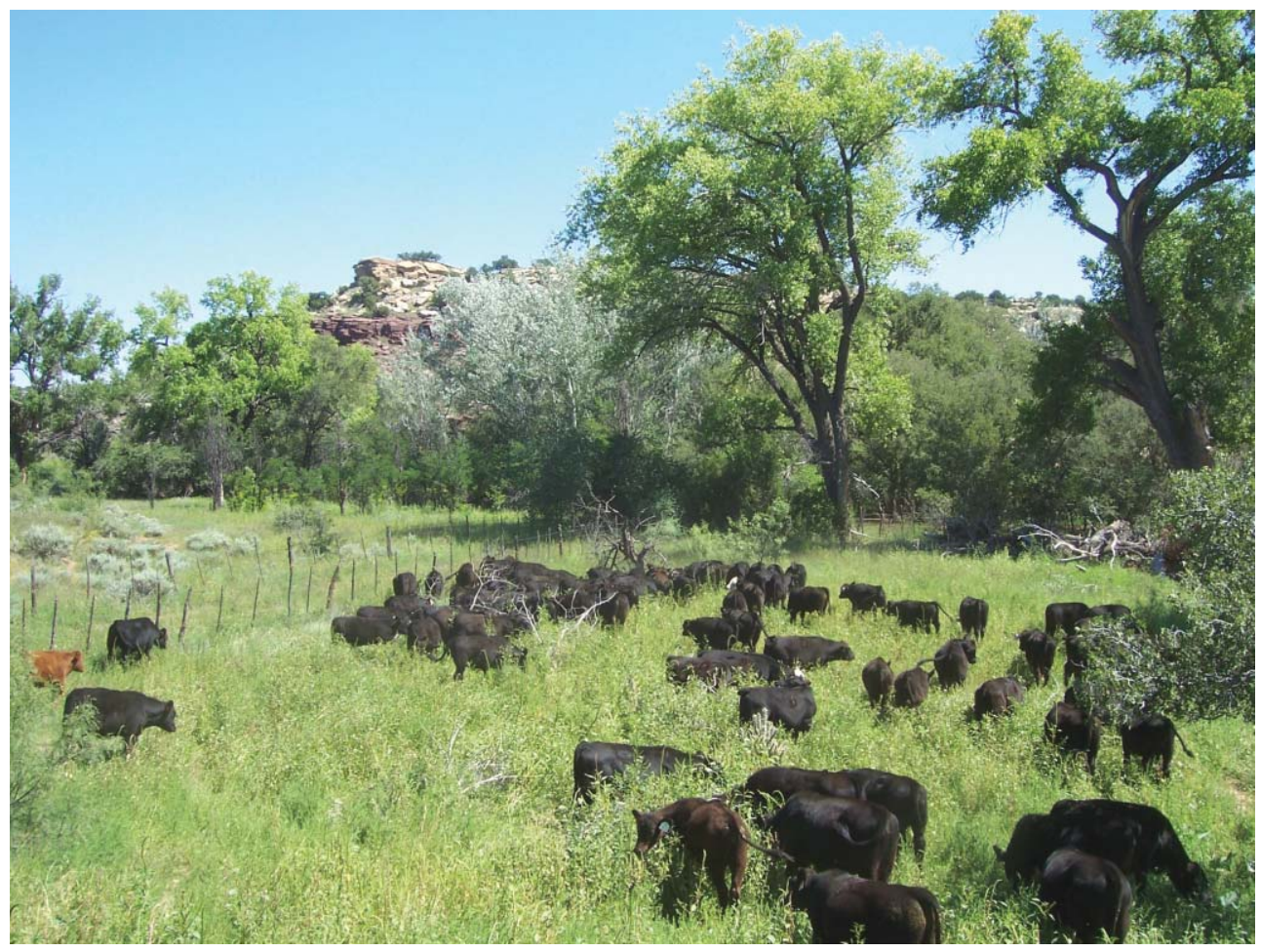

Concentrating livestock can increase utilization of forage resources, such as Kochia. Photo courtesy of Jim Thorpe. 